\title{
Dynamics of COVID-19 transmission in Dhaka and Chittagong: Two business hubs of Bangladesh
}

\author{
Zakaria Shams Siam $^{\mathrm{a}}$, Md. Arifuzzaman ${ }^{\mathrm{b}}$, Md. Salik Ahmed ${ }^{\mathrm{b}}$, Faisal Ahamed Khan ${ }^{\mathrm{c}}$, \\ Md. Harunur Rashid ${ }^{\mathrm{b}}$, Md. Shariful Islam ${ }^{\mathrm{b}, *}$ \\ ${ }^{a}$ Department of Electrical and Computer Engineering, North South University, Dhaka, Bangladesh \\ ${ }^{\mathrm{b}}$ Department of Mathematics and Physics, North South University, Dhaka, Bangladesh \\ c Giga Tech Ltd, Dhaka, Bangladesh
}

\section{A R T I C L E I N F O}

\section{Keywords:}

COVID-19

Epidemic model

SARS-CoV-2

Lockdown

Bangladesh

\begin{abstract}
A B S T R A C T
Background: Having inadequate health care systems and poor socio-economic infrastructure, Bangladesh has been braving to contain the impact of current COVID-19 pandemic since March, 2020. To curb the diffusion of COVID-19, the local government has responded to the outbreak by enforcing a set of restricted measures on economic and social activities across the country.

Objectives: Here, we aim to assess the propagation of COVID-19 by estimating the coronavirus active cases and mortality rate in two major business hubs of Bangladesh, namely Dhaka and Chittagong city under flexible lockdown conditions.

Methods: We apply a data-driven forecasting model using Susceptible, Exposed, Infected, Recovered and Deaths status through time to deal with coronavirus outbreak.

Results: The epidemiological model forecasts the dire consequences for Dhaka city with 2400 death cases at the end of December, 2020, whereas Chittagong city might experience 14\% more deaths than Dhaka if the severe restrictions are not implemented to control the pandemic.

Conclusion: Although lockdown has a positive impact in reducing the diffusion of COVID-19, it is disastrous for human welfare and national economies. Therefore, a unidirectional decision by the policymakers might cost a very high price on either way for a lower-middle-income country, Bangladesh. In this study, we suggest a fair trade-off between public health and the economy to avoid enormous death tolls and economic havoc in Bangladesh.
\end{abstract}

\section{Introduction}

The global community has been encountering an unpredicted and challenging outbreak in the world's history due to a Severe Acute Respiratory Syndrome Coronavirus (SARS-CoV-2019) since December 2019. ${ }^{1}$ The entire world has turned into a halt as the coronavirus disease 2019 (COVID-19) threatens to cause a humanitarian crisis. China, several countries of Europe and America have witnessed the highest number of deaths due to COVID-19 in the world, while more South-Asian countries, including, India, Pakistan, and Bangladesh are confirming a surge in cases. ${ }^{2}$ In serious COVID-19 positive cases, patients experience acute respiratory distress syndrome (ARDS), failure of different organs, and heart failure which might lead to fatal death. ${ }^{3,4,5}$ As the novel pathogen transmitted across the world in a short time, the
World Health Organization (WHO) affirmed the COVID-19 problem as a public health emergency at the end of January $2020.6,7$

Dhaka, the capital of Bangladesh, has been braving the COVID-19 crisis on all fronts since March, 2020. ${ }^{8}$ The first three COVID-19 positive cases were confirmed in Dhaka on March 8th, 2020 and since then, the capital emerges as Bangladesh's major epicenter of COVID-19 with 15760 active cases as of June 27 th, $2020 .{ }^{9}$ The health care system of the capital is not to the level of standard because of the scarcity of skilled workforce and inadequate health care services, albeit the Bangladesh government is reinforcing to fill up the gaps in the national health care system. ${ }^{10}$ Moreover, in case of an emergency condition like the current pandemic, Dhaka has only 169 ICU beds for the population of 21 million ("The Business Standard", June 26, 2020). Hence, it is an uphill task to attenuate the COVID-19 outbreak in Dhaka with its limited resources. ${ }^{11}$

\footnotetext{
* Corresponding author.

E-mail address: Shariful.islam10@northsouth.edu (Md.S. Islam).
} 
On March 26, 2020, a nationwide lockdown was first implemented by the Bangladesh government to confine the spread of COVID-19 cases with several strict policies that include home quarantine, social distancing and banning of national or international flight. However, some drawbacks have been noticed including the lack of testing kits, finding false taste, limited health equipment's for medical staff, lack of ICU with ventilation supports for emergency patients, and so on. ${ }^{12}$ Despite a surge in coronavirus cases even under confinement conditions, recently the government has decided to lift the lockdown gradually by reopening all the offices, markets and industries with a notable exception of educational institutions. Therefore, it is high time to evaluate the COVID-19 transmission trend in Bangladesh. To assess the infection spread, death tolls and other associated factors of any epidemic, a proper mathematical model can play a major role in predicting realistic, quantitative estimates. Therefore, various data-driven forecasting models have been applied to portray the progressive transmission of COVID-19 by several research groups. ${ }^{13-17}$

In this study, we aim to provide theoretical evidence on the dynamics of COVID-19 transmission in Dhaka and Chittagong by using the Susceptible-Exposed-Infected-Recovered-Dead (SEIRD) differential model. ${ }^{18}$ We further consider the daily time series data of active COVID-19 cases from Dhaka and Chittagong to assess the disease spread and predict the death peak under the severity of the flexible containment measures.

\subsection{Model and methods}

The SEIRD model is used to predict the epidemic diseases spreading through infected people over time. A homogeneous immunity is considered for the whole country and no significant variation between natural death and birth rate. There are five important variables needed to design the SEIRD model: $S, E, I, R$, and $D$, all of which are a function of time. The term $S(t)$ stands for the susceptible population, $E(t)$ denotes the number of exposed people (the individuals who have already been infected by the disease and potential candidates to spread it through the community people, but still asymptomatic), $I(t)$ represents the infected population, $R(t)$ signifies the number of people who have already recovered and no possibility to infect others and $D(t)$ means the death individuals. The total population at time $t: N(t)=S(t)+E(t)+I(t)+$ $R(t)+D(t)$. A set of ordinary differential equations is used to combine all stated variables in the SEIRD model to estimate the COVID-19 outbreak in Dhaka and Chittagong (See supplement).

\section{Results}

\subsection{The estimation of COVID-19 transmission under flexible lockdown in Dhaka}

Lockdown has played a key role in reducing the COVID-19 transmission in some countries, such as China and Italy, albeit there are some arguments regarding the negative impact of lockdown on the national economy. ${ }^{19-21}$ Notably, Hoque and colleagues recently demonstrated that only $10.2 \%$ of the total coronavirus cases are identified within the age group of $1-20$, the group that carries the major portion $(43.5 \%)$ of total age distribution of the population in Bangladesh. ${ }^{22}$ Since all the educational institutions are closed in an effort to stop the spread of coronavirus, one might ask whether the country is experimenting with a flexible approach and if so, then what would be the consequences on the public health in Dhaka city by considering the relaxed lockdown scenarios. In this note, we examine the dynamics of the current pandemic in Dhaka city under flexible lockdown conditions. To illustrate the spread of COVID-19 transmission, the SEIRD model simulations are performed in the GNU octave (Version 5.2.0) and Maple programming language environment. At first, we examine the COVID-19 dynamics for Bangladesh to determine all the epidemiological parameters which provide the best fit to the model relative to actual COVID-19 case data
(Suppl. Fig. 1). In total, 17 million population $(\sim N / 10, N$ is the total population of Bangladesh) is considered as the susceptible population $\left(S_{0}\right)$ for Bangladesh. Time-dependent effective reproduction number, $R_{e}$, is chosen at different phases of the outbreak. For instance, based on the real data, the $\mathrm{R}_{\mathrm{e}}$ was set in the range $2.50 \leq \mathrm{R}_{\mathrm{e}} \leq 3.80$ at the beginning of the outbreak similar to another study, ${ }^{23}$ whereas we assume a gradual attenuation $\left(0.95 \leq R_{e} \leq 3.8\right)$ during flexible lockdown for the next 150 days (1st August- 30th December). We postulate that a high transmission level will be substantially modified once the lockdown is relaxed. Next, we wish to estimate the COVID-19 transmission for Dhaka and Chittagong. Unfortunately, the raw data of COVID-19 active cases, death cases and the recovered cases are incomplete as well as not available for the individual cities. Therefore, we consider the COVID-19 modeling data from the Bangladesh and apply all epidemiological factors to forecast the outbreak for Dhaka and Chittagong city.

We set 2.1 million population as the susceptible population $\left(\mathrm{S}_{0}\right)$ for Dhaka city. Thus, considering the relaxed lockdown conditions, the SEIRD model predicts around 13500 corona positive cases on 30th October, 2020 with a daily death toll going as high as 25 deaths in Dhaka city (Fig. 1A and B). Moreover, we hypothesize that the outbreak can be further delayed in Dhaka by extending the confinement until December 30th, 2020. As a result, we estimate a total active case of 10500 and a death toll of 2400 at the end of December, 2020. These results illustrate the fact that implementing flexible lockdown will not work alone to diminish the pandemic in Dhaka due to its high dense population. Taken together, the model exclusively forecasts the COVID-19 outbreak for Dhaka under flexible lockdown conditions.

\subsection{How well Bangladesh's other business hub, Chittagong, is doing under lockdown conditions?}

Chittagong is the second-largest city in Bangladesh that has an immense role in the regional connectivity across the Indian subcontinent. The port city, Chittagong, witnessed its first coronavirus positive case on April 2nd, 2020. Here, we further apply the existing approach and project the COVID-19 spread for Chittagong city considering the similar restrictions. Our model estimates $\sim 9000$ active cases with $\sim 2250$ deaths in this city at the beginning of November if the disease transmission continues with the current trend (Fig. 2A and B). Furthermore, if the confinement continues for the next 60 days (November-December), the port city might hit the death peak $(\sim 2800)$ in the first week of January, 2021 compared to the death peak $(\sim 2450)$ of Dhaka city (Fig. 2B). Hence, Chittagong could have 14\% more death tolls relative to Dhaka city if the transmission follows the similar trend until 30th December, 2020.

\section{Discussion}

The COVID-19 health emergency has hit Bangladesh's economy hard on a scale not seen in living memory. This global crisis has jeopardized country's remarkable triumph in poverty reduction. Dhaka is the major financial and commercial hub of Bangladesh as it holds up to $35 \%$ of the country's economy. ${ }^{24}$ Therefore, evaluation of COVID-19 dynamics is of great importance for the capital since it can guide the local community towards the use of basic resources in an efficient way to attenuate the transmission. In this manuscript, we provide the theoretical prediction concerning the COVID-19 positive cases and mortality rates in Dhaka and Chittagong city. Our analysis forecasts that Chittagong might experience enormous death tolls compared to Dhaka, if the diffusion continues at the same pace. Therefore, Chittagong needs an immediate implementation of proper lockdown, considerable guidance and a prepared health care system to save the senior citizens. Moreover, large scale testing capacities are required to mitigate the community diffusion in these cities. As we have inadequate RT-PCR based COVID-19 testing lab, the Government must introduce low-cost rapid antibody/antigen test kits. Notably, the public mobility is on the rise in these two business 
A)

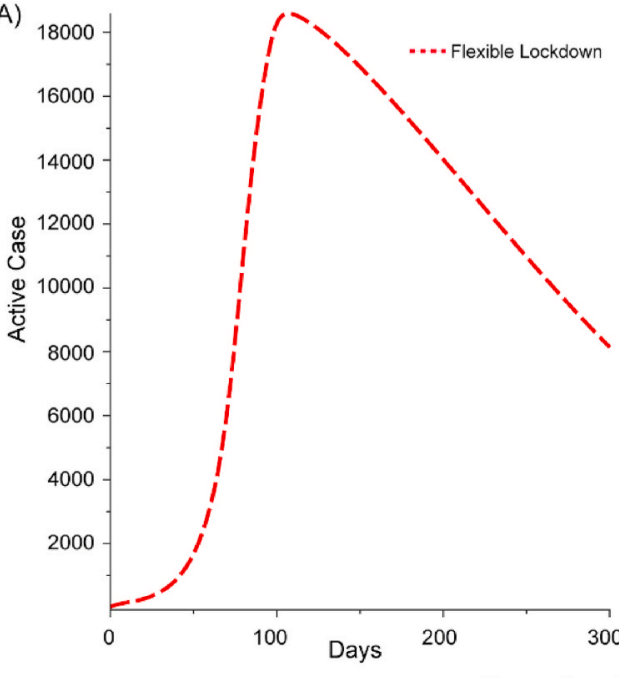

B)

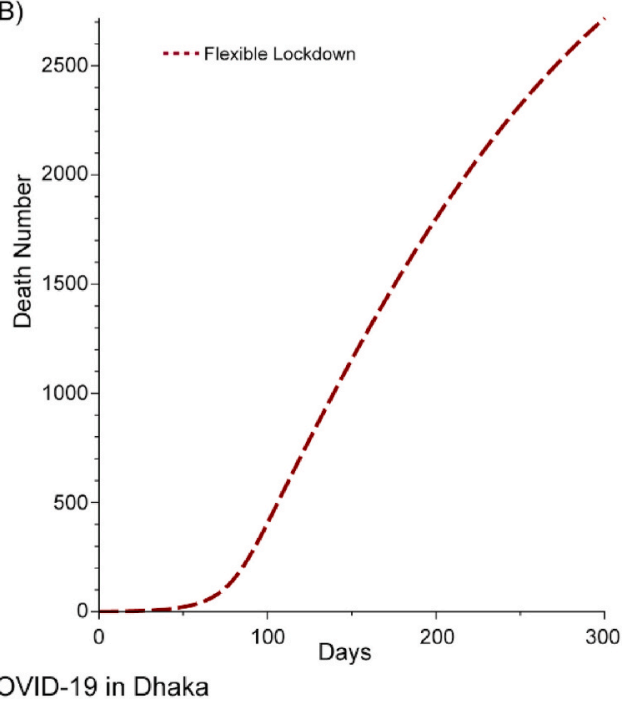

Fig. 1. The dynamics of COVID-19 on corona active cases and death cases in Dhaka. A-B) Dynamics of the infected population and death tolls as a function of time, when the flexible lockdown are imposed.
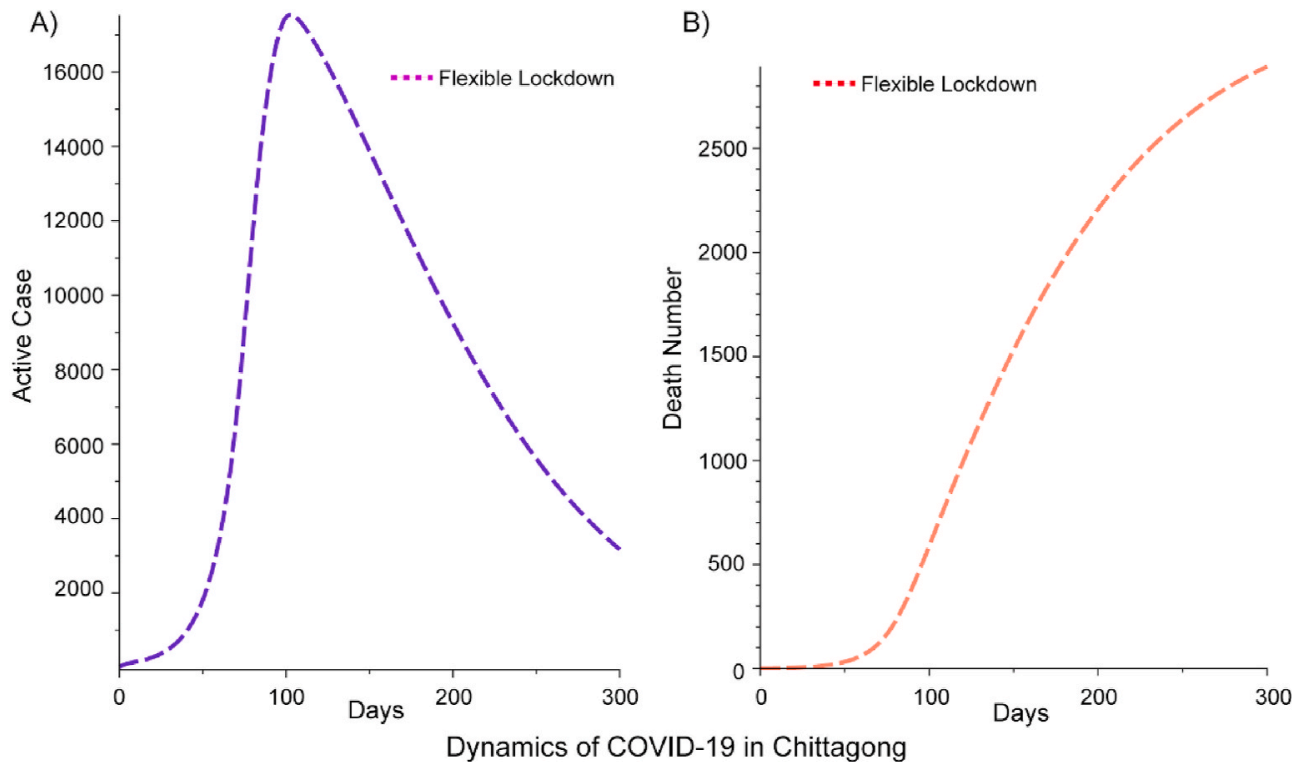

Fig. 2. COVID-19 progression in Chittagong city. A-B) Progression of infected population and death tolls as a function of time in Chittagong city under flexible lockdown conditions.

hubs and thus, zone-coded lockdown needs to be implemented again in small areas within the city. Furthermore, according to the results of this manuscript, these cities should prevent intercity movements as much as possible to reduce the infection rate until the situation turns into normalcy. Glaecer and colleagues report that New York City could have controlled the high rate of COVID-19 positive cases by enforcing the strict confinement and proper public mobility suspension. ${ }^{25}$ Last but not least, each COVID-19 case data should be collected on time, analyzed centrally and should be available for the researchers. These accessible raw data will help the scientists to predict the onset of pandemic in any region as well as to arrange the appropriate health intervention for different zones based on the need. Nevertheless, neglecting the economic aspects of the pandemic and excluding the questions it raises might lead a nation towards an uncertain economic landscape. Therefore, one also needs to consider all the economic indicators in this global crisis. For example, high-income countries such as France might experience a 3\% reduction of Gross Domestic Product (GDP) due to a month long confinement according to the INSEE (Institut national de la statistique et des études économiques), whereas the cost will be even higher for low-income countries. ${ }^{26}$ Strikingly, Gross Domestic Product (GDP) in Bangladesh is expected to grow by $3.8 \%$ at the end of 2020 due to its impressive macroeconomic performance. ${ }^{27}$ Our mathematical projection might contribute to the current argument concerning the demand for the policy, although the negative impact of strict lockdown on the local economy was not considered in our study. To keep a healthy trade-off between health and the economy, we believe that any decision on two dimensions of this pandemic should be considered meticulously to get the full advantage of confinement in terms of shrinking the COVID-19 death cases in these two major cities of Bangladesh. Regardless of the above strategy, there are several things to concern about the overall pandemic scenario in Bangladesh. As Bangladesh is going through an emergency condition, we have very primary and incomplete COVID-19 data. Therefore, our analysis might not exemplify the pandemic situation accurately. Taken together, we are hopeful that 
our data-driven analysis is useable for the policy speculation and controlling the disease transmission for future outbreaks in Bangladesh.

\section{Author's contributions}

ZS, MA, MI made substantial contributions to the conception or design of the work. ZS and FK completed the relevant studies and created plots related to the SEIRD estimation, while MA and MI wrote the draft. MR and MSA critically revised the manuscript. All the authors met regularly to discuss the outcome of each experiment. The data were collected from the IEDCR website and each of the results was cross checked by at least three of the six authors. All authors are responsible for acquiring, analyzing, and interpreting the data for this article.

\section{Funding}

The authors declare that no funding was received to pursue this research.

\section{Availability of data and materials}

All data were collected from the IEDCR, Bangladesh website.

\section{Ethics approval and consent to participate}

Not applicable.

\section{Consent for publication}

Not applicable.

\section{Declaration of competing interest}

The authors declare that the research was conducted in the absence of any commercial or financial relationships that could be construed as a potential conflict of interest.

\section{Acknowledgement}

The authors would like to thank Dr. Fariha Jasmin Chowdhury and Md. Waliullah for their critical comments as a general reader.

\section{Appendix A. Supplementary data}

Supplementary data to this article can be found online at https://doi. org/10.1016/j.cegh.2020.100684.

\section{References}

$1 \mathrm{Lu} \mathrm{H}$, Stratton CW, Tang YW. Outbreak of pneumonia of unknown etiology in Wuhan, China: the mystery and the miracle. J Med Virol. 2020 Apr;92(4):401-402.
2 Shams SA, Haleem A, Javaid M. Analyzing COVID-19 pandemic for unequal distribution of tests, identified cases, deaths, and fatality rates in the top 18 countries. Diabetes Metabol Syndr Clin Res Rev. 2020 Sep 1;14(5):953-961.

3 Cascella M, Rajnik M, Cuomo A, Dulebohn SC, Di Napoli R. Features, Evaluation and Treatment Coronavirus (COVID-19). StatPearls Publishing; 2020 Mar 8. InStatpearls [internet].

4 Rocke J, Hopkins C, Philpott C, Kumar N. Is loss of sense of smell a diagnostic marker in COVID-19: a systematic review and meta-analysis. Clin Otolaryngol. 2020 Aug 1;45 (6):914-922.

5 Multisystem inflammatory syndrome in children and adolescents temporally related to COVID-19. Retrieved www.who.int. Accessed May 20, 2020.

6 How to Protect Yourself \& Others: Centers for Disease Control and Prevention (CDC). Archived from the Original on 26 February 2020. 8 April 2020. Retrieved 9 April 2020.

7 Statement on the second meeting of the International Health Regulations (2005). Emergency Committee Regarding the Outbreak of Novel Coronavirus (2019-nCoV): World Health Organization(WHO). Archived from the Original on 31 January 2020. 2020. Retrieved 11 February.

8 Population \& Housing Census-2011: Bangladesh Bureau of Statistics. 2015:41. Archived from the original (PDF) on 8 December 2015. Retrieved 15 December.

9 COVID-19 in Dhaka: case rates. https://bengal.institute/research/covid19dhaka/.

10 Ahmed SM, Hossain MA, RajaChowdhury AM, Bhuiya AU. The health workforce crisis in Bangladesh: shortage, inappropriate skill-mix and inequitable distribution. Hum Resour Health. 2011 Dec 1;9(1):3.

11 Islam MT, Talukder AK, Siddiqui MN, Islam T. Tackling the Pandemic COVID-19: The Bangladesh Perspective.

12 Manzur H. Maswood, Only 112 ICU beds for coronavirus patients in Bangladesh. New Age Bangladesh. 8 April 2020.

13 Roosa K, Lee Y, Luo R, et al. Real-time forecasts of the COVID-19 epidemic in China from February 5th to February 24th, 2020. Infect Dis Model. 2020 Jan 1;5:256-263.

14 Xie J, Tong Z, Guan X, Du B, Qiu H, Slutsky AS. Critical care crisis and some recommendations during the COVID-19 epidemic in China. Intensive Care Med. 2020 Mar 2:1-4.

15 Phua J, Weng L, Ling L, et al. Intensive care management of coronavirus disease 2019 (COVID-19): challenges and recommendations. Lancet Respir Med. 2020 Apr 6;8(5): 506-517.

16 Gupta R, Pandey G, Chaudhary P, Pal SK. SEIR and Regression Model based COVID19 outbreak predictions in India. medRxiv. 2020 Jan 1.

17 Lourenco J, Paton R, Ghafari M, et al. Fundamental principles of epidemic spread highlight the immediate need for large-scale serological surveys to assess the stage of the SARS-CoV-2 epidemic. MedRxiv. 2020 Jan 1.

18 Weitz JS, Dushoff J. Modeling post-death transmission of Ebola: challenges for inference and opportunities for control. Sci Rep. 2015 Mar 4;5:8751.

19 Figueiredo AM, Daponte Codina A, Figueiredo M, Saez M, Cabrera León A. Impact of lockdown on COVID-19 incidence and mortality in China: an interrupted time series study. Bull World Health Organ. 2020.

20 Lau H, Khosrawipour V, Kocbach P, et al. The positive impact of lockdown in Wuhan on containing the COVID-19 outbreak in China. J Trav Med. 2020 Apr;27(3):taaa037.

21 Siam ZS, Arifuzzaman M, Rashid MH. No lockdown policy for COVID-19 epidemic in Bangladesh: good, bad or ugly? medRxiv. 2020 Jan 1.

22 Hoque E, Islam MS, Amin MR, Das SK, Mitra DK. Adjusted dynamics of COVID-19 pandemic due to herd immunity in Bangladesh. medRxiv. 2020 Jan 1.

23 Chatterjee S, Sarkar A, Chatterjee S, Karmakar M, Paul R. Studying the progress of COVID-19 outbreak in India using SIRD model. medRxiv. 2020 Jan 1.

24 Karim Rezaul, February. Dhaka's Economic Activities Unplanned: Analysis: The Daily Star. 2017.

25 Glaeser EL, Gorback CS, Redding SJ. How much does covid-19 increase with mobility? evidence from New York and four other us cities. Nat Bureau Econ Res. 2020 Jul 9, w27519.

26 Pricing lives in the time of COVID-19, SciencesPro: center for internationl studies. https://www.sciencespo.fr/ceri/en/content/pricing-lives-time-covid-19.

27 Why Bangladesh GDP is projected to grow despite COVID-19. Financ Express. October $23,2020$. 